\title{
The Impact of an Online Happiness Course on Subjective Happiness Among College Students
}

\author{
Casey Murdoch Rodowicz, BA \\ University of North Carolina Wilmington \\ Laura Morris, Ed.D \\ University of North Carolina Wilmington \\ Cara L. Sidman, PhD \\ Arizona State University \\ Kelsey Beyer, MS
}

\begin{abstract}
Background: This research examined the subjective happiness of students enrolled in either a 5-week happiness or a 5-week recreational course, both administered online. Studies have shown improvements in college students' well-being after teaching them behavior modification strategies, in a face-to-face setting, similar to those implemented in the present study. In addition, the past three decades of research on positive psychology has provided extensive evidence of the beneficial impact of happiness, or positive psychological interventions (PPIs), on various aspects of well-being. These include emotional variables related to stress.
\end{abstract}

Aim: The purpose of this study was to determine the impact of an evidence-based online happiness course on subjective happiness among college students.

Methods: Participants $(\mathrm{N}=74)$ were self-selected based on course enrollment. The population of interest was college students $(18-22$ years of age). An online survey methodology was utilized for data collection of pretest/posttest measures of subjective happiness.

Results: Participants in both the happiness and recreational courses reported increased measures of subjective happiness, although there was no significant difference between group means

Conclusion: Future research investigating university-based happiness courses and other interventions, using a variety of delivery formats, is recommended to determine the most effective ways to improve overall happiness in student populations.

Submitted 29 August 2019: accepted 12 November 2019

Keywords: college student happiness, wellness, online, intervention, stress

Happiness plays a key role in physical and mental health. The happier people are, the healthier they are emotionally and physically, and their ability to cope improves. Cohn, Fredrickson, Brown, Mikels, and Conway (2009) found "happy people become more satisfied not simply because they feel better, but because they develop [resilience]" (p. 1). Psychological disorders, disease, and interpersonal relationships all benefit when personal happiness elevates. Seligman (2004) posited that just as psychology could teach individuals to overcome difficulties (such as mental 
illness), strategies could be taught to improve happiness. According to Lyubomirsky (2007), most of the strategies shown to improve happiness also manage stress. One of the foundations for positively impacting the $40 \%$ of happiness within personal control is the implementation of effective coping strategies, also referred to as managing stressful demands.

\section{BACKGROUND AND LITERATURE REVIEW}

A population that may particularly benefit from instruction on how to be happy is college students, especially given the amount of stress in their lives. University students, and all young adults, are especially vulnerable to depression and emotional hardship as they navigate entry to adulthood. While exciting, this transition can also be stressful, anxiety-producing, and may trigger various forms of psychopathology (Tosevski, Milovancevic, \& Gajic, 2010). Young adults typically have a high rate of mental illness, including major depression and suicidal thoughts. In 2017, the National Institute of Mental Health recorded a $25.8 \%$ prevalence of mental illness in adults 18 - 25 years of age. Furthermore, adults aged 18 - 25 years had the highest rate of major depression in 2017 at 13.1\%, compared to $7.7 \%$ for ages 26-49 and 4.7\% for ages 50 and older. Young adults aged 18 - 25 years had nearly twice the prevalence of suicidal thoughts than other age groups at 10.5\% in 2017 (26-49=4.3\%; 50+ $=2.5 \%$ ). Adults between $18-25$ years of age also had the highest prevalence of suicide attempts in 2017 at $1.9 \%$, compared to $0.4 \%$ in ages 26 - 49 years and $0.3 \%$ in ages 50 years and older. The young adult suicide attempt rate is about four and a half times higher than that of the next age group. Moreover, there has been an unprecedented demand for counseling services on campuses nationwide as occurrences of depression and anxiety increase (Reilly, 2018). These statistics suggest young adult mental health is a pressing concern. Evidence-based happiness interventions may offer a way to improve the subjective happiness of college students. By doing so, educators and mental health professionals may gain insights to alleviate mental illness and stress and improve student well-being.

There is evidence to suggest that teaching health and wellness concepts, such as happiness and well-being, may be best delivered in an online environment due to its potential to make a widespread impact. Online courses are ubiquitous, with nearly 5.5 million undergraduates enrolled in an online course or online degree program in 2012, many of which are offered in the health and wellness sciences (U.S. Department of Education, National Center for Education Statistics, 2014). The widespread potential to positively influence the emotional well-being, happiness, and stress among college students through evidence-based online university course interventions is profound and in need of exploration.

Lambert, Passmore, and Joshanloo (2018) studied the impact of an evidence-based positive psychology intervention (PPI) delivered during a 14-week face-to-face university course to a diverse population of international students. Their "Happiness 101" program essentially involved the addition of happiness strategies, based on the theoretical framework of Seligman's PERMA Model, to their Introduction to Psychology courses. The variables of specific interest for intervention participants, compared to the control group, were eudaimonia, hedonia, fear of happiness, and fragility of happiness. Researchers reported that students exposed to the positive psychology interventions in their university course had significant increases in eudaimonic and hedonic happiness, and decreases in fear. The results provided evidence that happiness and stress levels can be changed among university students exposed to PPI interventions. In other words, happiness can be taught, and stress can be reduced, through the implementation of evidence-based strategies. 
The present study was interested in a PPI delivered to college students via an online format. Subjective happiness levels among university students were measured by a valid subjective happiness scale before and after participation. These scales were administered in either an online happiness course or an online recreation course serving as the comparison. It was hypothesized that: (a) subjective happiness levels would increase from pre- to post-intervention among participants enrolled in the online happiness courses, and (b) overall, participants in the online happiness courses would have significantly higher subjective happiness scores than those enrolled in the online recreation course.

\section{METHOD}

This study adopted a one-within one-between-groups, pre-test-post-test, design. The independent variable was courses type (HC1, HC2, and REC), and the dependent variable was subjective happiness.

A total of 74 undergraduate students from a southeastern public university participated. Participants were enrolled in online Happiness Course 1 (HC1), Happiness Course 2 (HC2), or a recreation course (RC). Both happiness courses were Creating Happiness \& Well-Being, while the recreation course was Sport, Culture, and Society. Students already enrolled in the courses were recruited to participate. Participants were allocated to each group based on their course enrollment, which was mutually exclusive. Participation in the pre/post-test survey was a requirement for each course. Figure 1 is the content of an email sent to participants providing them with an embedded link for survey access.

Figure 1. Email sent to students at the end of the semester (during the fifth week).

\section{Week 5 To-Do List}

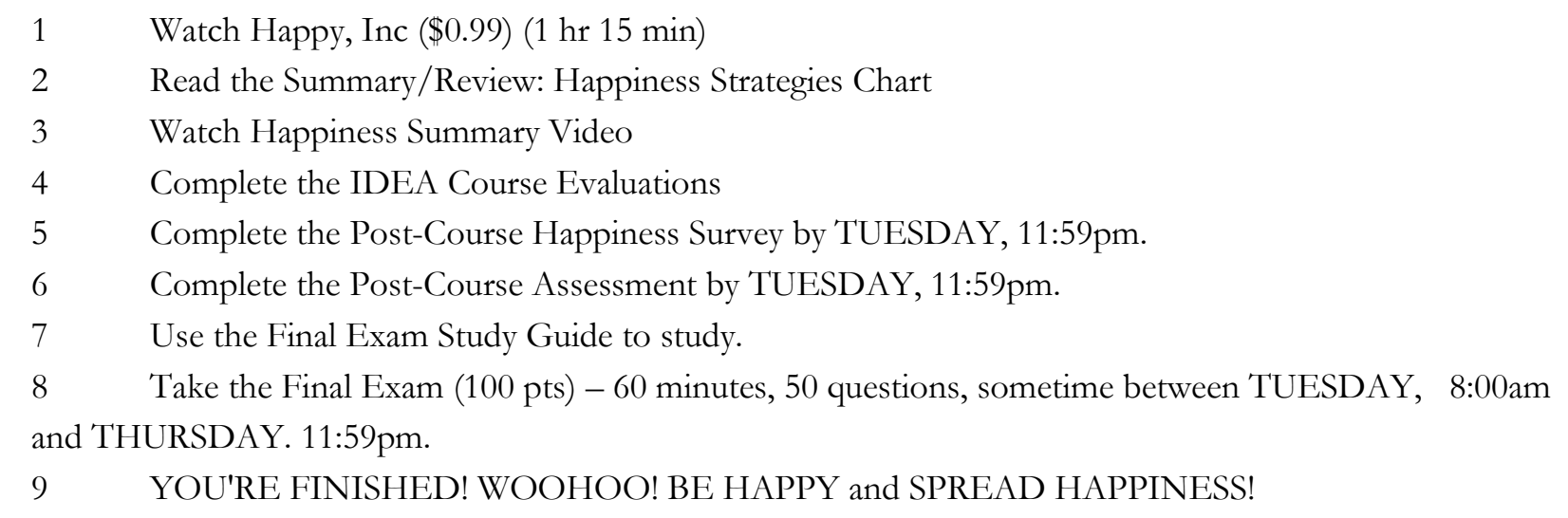

\section{Data Collection and Instrumentation}

Data was collected through Blackboard, the learning management system used by the University. The email feature in Blackboard Learn was used to send participants the survey, study information, and administer the survey. The Subjective Happiness Scale (SHS) measures individual happiness (Lyubomirsky \& Lepper, 1999) and was adapted to Blackboard. This included creating titles, questions and other information in an online format (Tests and Surveys, n.d.). Anonymity was preserved upon download with no trace to identify participant scores with names. 
Figure 2. Adapted from The Subjective Happiness Scale (Lyubomirsky \& Lepper, 1999)

For each of the following statements and/or questions, please circle the point on the scale that you feel is most appropriate in describing you.

1. In general, I consider myself:

\begin{tabular}{cccccccc}
$\begin{array}{c}1 \\
\text { not a very } \\
\text { happy } \\
\text { person }\end{array}$ & 2 & 3 & 4 & 5 & 6 & $\begin{array}{c}7 \\
\text { a very } \\
\text { happy } \\
\text { person }\end{array}$ \\
\hline
\end{tabular}

2. Compared with most of my peers, I consider myself:

$\begin{array}{cccccccc}\underset{c}{1} & 2 & 3 & 4 & 5 & 6 & \begin{array}{c}7 \\ \text { more } \\ \text { happy }\end{array} \\ \text { happy } & & & & & & & \end{array}$

3. Some people are generally very happy. They enjoy life regardless of what is going on, getting the most out of everything. To what extent does this characterization describe you?

$\begin{array}{ccccccc}1 & 2 & 3 & 4 & 5 & 6 & \begin{array}{c}7 \\ \text { a great } \\ \text { deal } \\ \text { all }\end{array}\end{array}$

4. Some people are generally not very happy. Although they are not depressed, they never seem as happy as they might be. To what extent does this characterization describe you?

$\begin{array}{ccccccc}\begin{array}{c}1 \\ \text { not at } \\ \text { all }\end{array} & 2 & 3 & 4 & 5 & 6 & \begin{array}{c}7 \\ \text { a great } \\ \text { deal }\end{array} \\ & & & & & & \end{array}$

Participants responded using a 7-point Likert-type scale, with 1 indicating low happiness and 7 indicating high happiness levels. The SHS has four items to examine the level of happiness experienced, such as [some] people are generally very happy. They enjoy life regardless of what is going on, getting the most out of everything. To what extent does this characterization describe you? (Lyubomirsky \& Lepper, 1999). This measurement has been widely employed in happiness or well-being based research (Bögels, Hoogstad, van Dun, de Schutter, \& Restifo, 2008; Kim \& Lee, 2011; Duckworth, Steen, \& Seligman, 2005). Test-retest reliability ranged from 0.55 to 0.90 ( $\mathrm{M}=0.72$ ), while convergent validity had correlations of 0.52 to $0.72(\mathrm{M}=0.62)$ and discriminant validity tests found all but one variable failed to reach statistical significance (Lyubomirsky \& Lepper, 1999). See Figure 2 for more detail. 


\section{Materials and Procedures}

The present study took place during three 5-week courses (HCI, HC2, and RC) between May - June 2016. The RC course focused on sport in society. It is described as a basic online lecture format. Both the RC and HCI/HC2 courses had a similar number of assignments and requirements for students to complete. HC1 and HC2 taught students research-based happiness strategies from Lyubomirsky's (2008) book, The How of Happiness, that has chapters devoted to happiness factors and offered specific strategies to increase individual happiness. For example, a chapter titled Practicing Gratitude and Positive Thinking addresses how to avoiding overthinking and social comparison (Lyubomirsky, 2008, p. 112). Lyubomirsky presents the scientific support for each strategy. Participants were asked each week of the course to incorporate three happiness-inducing strategies into their life. They were then required to complete a happiness blog and post submissions three times throughout the course. To earn full credit for each blog post, they needed to show clear evidence of participation in happiness strategies, show creativity and effort in blogging their happiness strategies, and maintain appropriate online etiquette. Options for blog posts included videos, written summaries, pictures, and more. Grading criteria included title, content, one relevant image, one external link, and comments. Participants completed Lyubomirsky and Lepper's (1999) Subjective Happiness Scale (Figure 2). The pretest self-assessment took place during the first 3 days of class and the post-test during the last three days of class.

\section{Data Analysis}

The independent variable was class type with three categories (HC1, HC2, and REC). The dependent variable was happiness measured on an ordinal scale. Initially, differences were established between pre-course and post-course for each item, and overall for each course. Using univariate statistics, the p-value was obtained from a signed rank test and was compared to the alpha-level of 0.05 to test the significance. SAS software version 9.4 (SAS) was utilized for data analysis. The procedures used in SAS were frequent, means, and univariate analysis. A signed rank test was also used to compare item scores. The values for Item 4 were reverse-coded as specified in the coding instructions. High scores represented a higher level of perceived happiness.

\section{RESULTS}

The SHS survey was distributed online at the start of each course, and 28 students in HCI, 27 students in HC2, and 19 students in RC completed the initial pre-test survey. Attrition resulted in smaller sample sizes for the post-test selfassessment in each category $(\mathrm{HC} 1=27, \mathrm{HC} 2=24, \mathrm{RC}=16)$. Figure 3 presents the means and standard deviations for each course pre and post. All means increased from pre to post assessment measures for each course. Figure 3 shows the increase in total mean scores for all three courses. The mean survey scores for HC1 also demonstrated a significant increase pre-test to post-test $(\mathrm{p}=.0341)$. There was no significant difference between the means of the courses. 
Table 1

Total Means and Standard Deviations of Each Class During Both the Pre-Test and Post-Test Phase

CHHS292-800

\begin{tabular}{|c|c|c|c|c|c|}
\hline Pre-test & Post-test & Pre-test & Post-test & Pre-test & Post-test \\
\hline Mean $\pm S D$ & Mean $\pm S D$ & Mean $\pm S D$ & Mean $\pm S D$ & Mean $\pm S D$ & Mean $\pm S D$ \\
\hline $4.8 \pm 0.7$ & $5.2 \pm 0.8$ & $4.4 \pm 1.0$ & $4.9 \pm 0.9$ & $4.8 \pm 0.9$ & $5.2 \pm 0.7$ \\
\hline
\end{tabular}

Figure 3. Total scores of all questions from the pre-test phase to the post-test phase.

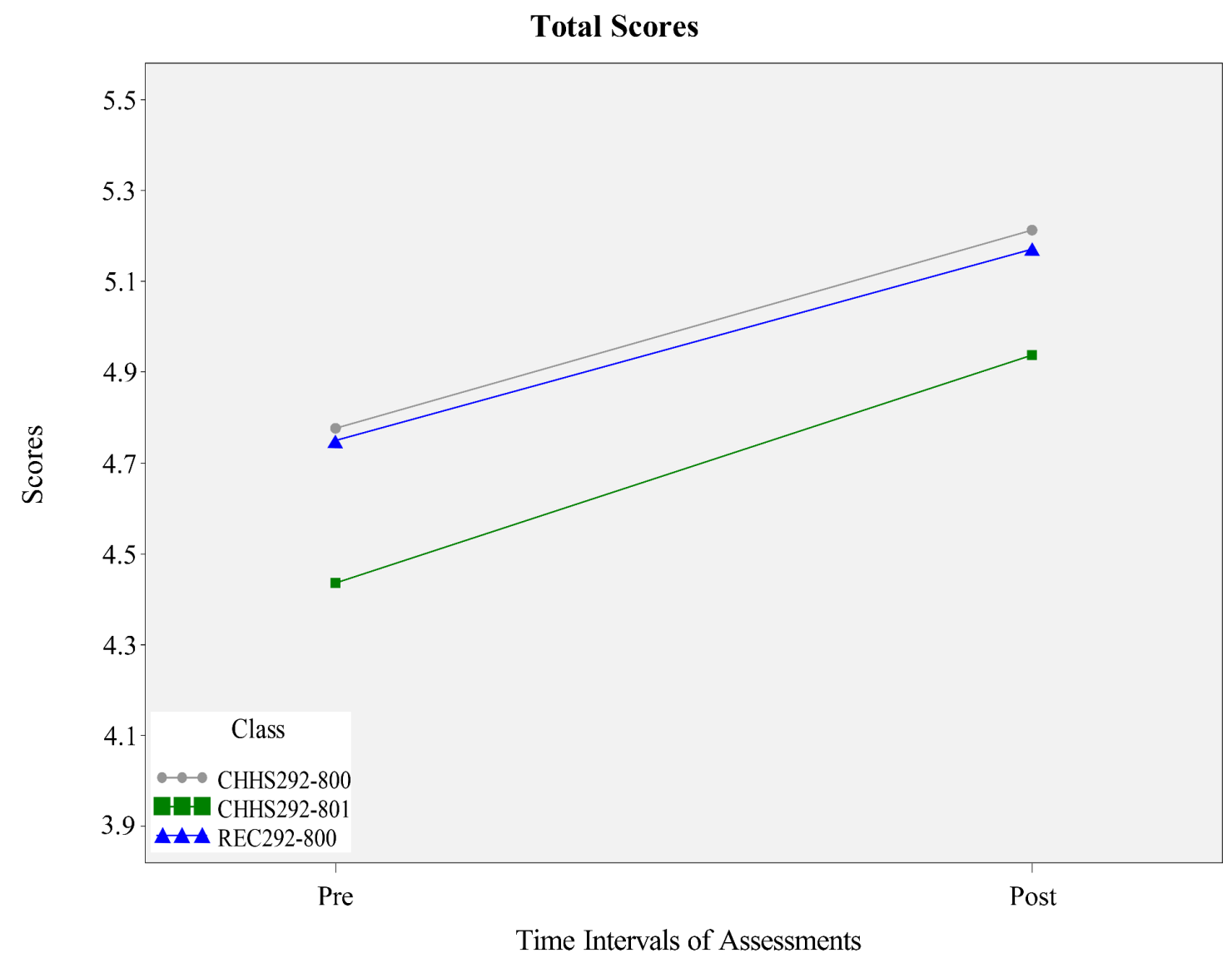


Table 2

Mean and Standard Deviations of Each SHS Question, Classified by Both Class and Testing Phase (Pre and Post) SHS Item Score Average Change from Pre to Post

\begin{tabular}{|c|c|c|c|c|c|c|}
\hline \multirow[t]{2}{*}{ Item } & \multicolumn{2}{|c|}{ CHHS 292-800 } & \multicolumn{2}{|c|}{ CHHS 292-801 } & \multicolumn{2}{|c|}{ REC 292-800 } \\
\hline & Pre & Post & Pre & Post & Pre & Post \\
\hline 1 & $5.6 \pm 1.1$ & $5.8 \pm 1.6$ & $5.3 \pm 1.4$ & $5.9 \pm 1.1$ & $5.8 \pm 1.4$ & $6.4 \pm 0.7$ \\
\hline 2 & $5.2 \pm 1.1$ & $5.9 \pm 1.2$ & $4.9 \pm 1.4$ & $5.6 \pm 1.3$ & $5.1 \pm 1.7$ & $5.9 \pm 0.8$ \\
\hline 3 & $5.2 \pm 1.5$ & $5.8 \pm 1.2$ & $4.6 \pm 1.7$ & $5.5 \pm 1.4$ & $5.5 \pm 1.1$ & $5.8 \pm 0.9$ \\
\hline 4 & $3.2 \pm 1.7$ & $3.4 \pm 1.9$ & $2.9 \pm 1.5$ & $2.7 \pm 1.6$ & $2.6 \pm 1.2$ & $2.6 \pm 1.9$ \\
\hline
\end{tabular}

Note: Means are followed by \pm to indicate standard deviation.

For specific questions of the SHS survey, Item 2 yielded significant differences from the pre-test to the post-test. Item 2 asked: Compared with most of my peers, I consider myself... and then participants selected a level of happiness on a 7-point scale. The mean score for item 2 significantly increased from pre to post assessment for the HC1 group (p $=.0077)$ and for the RC group ( $\mathrm{p}=.0371$ ). Figure 4 shows the significant increase for item 2 for HC1 and RC.

Figure 4. Question 2 scores from the pre-test phase to the post-test phase.

\section{Question 2}

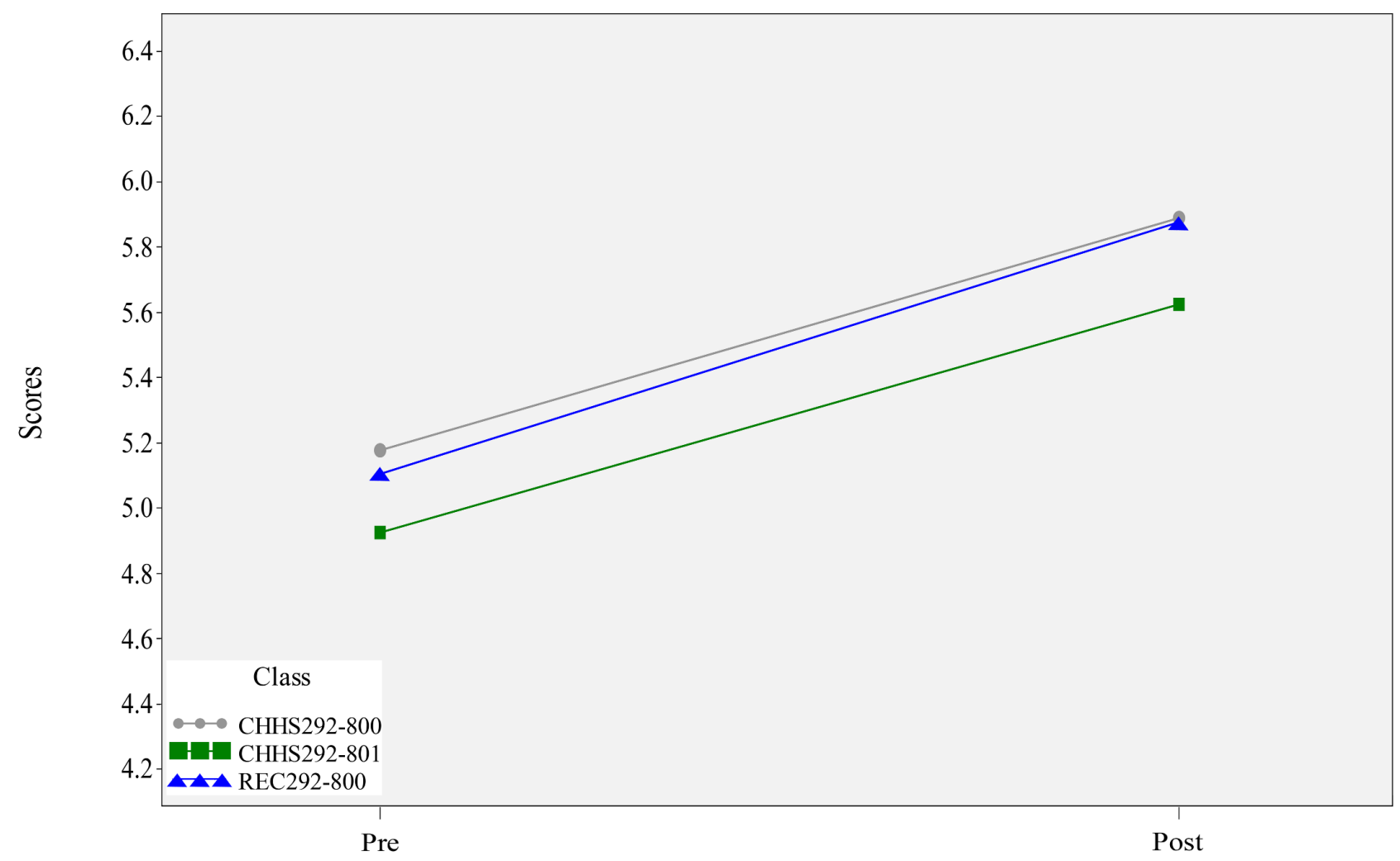

Time Intervals of Assessments 


\section{DISCUSSION}

Differences in subjective happiness were compared at the start and after 5 weeks among college students enrolled in two online happiness courses and an online recreation course. The research questions examined (a) whether participation in an online happiness course enhanced subjective happiness scores, and (b) whether participants in the happiness categories reported significantly different scores than those enrolled in an online recreation course. Subjective happiness scores increased in all categories but there was no significant difference between groups implying extraneous factors may have influenced participants' subjective happiness.

When examining total scores, the HC1 total pre-survey mean was significantly different from the HC1 total postsurvey mean $(\mathrm{p}=.0341)$. This demonstrates that the Creating Happiness \& Well Being course may have increased participant happiness; however, the RC course survey means were extremely close to the HC1 means, indicating course content may not have been a factor. The significant differences between groups on item 2 further indicates both happiness and recreational groups reported an increase in happiness. While the happiness interventions may have affected participant well-being, so did the recreation course, thus warranting further research.

A noticeable finding of the current study is the similarity of results between happiness and recreational groups. The pre-test means of $\mathrm{HC} 1$ and $\mathrm{RC}$ were the same $(\mathrm{M}=4.8, \mathrm{SD}=.07 ; \mathrm{M}=4.8, \mathrm{SD}=.09)$, while the HC2 mean was slightly lower $(\mathrm{M}=4.4, \mathrm{SD}=1.0)$. The post course means of $\mathrm{HC1}$ and $\mathrm{RC}$ were again the same $(\mathrm{M}=5.2, \mathrm{SD}=0.8$; $\mathrm{M}=5.2, \mathrm{SD}=0.7)$. HC2 post course mean was again slightly lower $(\mathrm{M}=4.9, \mathrm{SD}=0.9)$. This poses a problem. First, the sample size may have been too small and the course length too short. Collecting data on more participants over longer 15-week semesters may yield different results. The additional participants, plus the longer time for students to participate in the happiness strategies, may better delineate differences between online happiness course participants and students in an online recreation course. Secondly, a campus-wide extension of the survey would allow students in unrelated classes to participate. This may allow differences to become prevalent between happiness and recreation groups, and also may be more representative of the true effect of the happiness strategies involved in the course.

Unfortunately, the results may have been confounded by the timing of when surveys were administered. This could be the reason why scores were high for both classes. Student levels of happiness were elevated prior to the semester, as well as afterwards, when their stress levels were most likely lower. Although future research would need to be conducted collecting specific data on stress, many professors can attest to anecdotal reports of students being happier and less stressed at the end of a semester. A solution may be to administer the scale monthly throughout the semester. Yet the fact that students are generally happier when taking a course is a natural confounder that must be accounted for when examining the final data.

Lastly, the data collected were part of coursework, and demographics were not included. However, future research collecting this type of information, including age, sex, and class year may provide additional insight into potential differences in happiness between groups. For example, while satisfaction scores between online and face-to-face courses were not significantly different in Block, Udermann, Felix, Reineke, and Murray's (2008) study, there were contrasting demographics between groups. Students in online courses tended to be employed, older, and had completed more schooling than students taking in-person classes (Block, Udermann, Felix, Reineke, \& Murray, 2008). It would be interesting to research these demographics with a larger sample size. With regard to the evidence of online courses providing as rich a learning experience as traditional courses, it would be logical to assume the similarity between groups was not due to the online format. However, using face-to-face courses for a control group regarding both happiness and unrelated content might address this issue. 
Interestingly, other research using the SHS (Lyubomirsky \& Lepper, 1999) revealed an average college student score of approximately 4.88 (moderate to high happiness). The average score of students in the present study was 4.66 pre-test and 5.05 during post-test (see Figure 4). Fluctuation of scores from below the college average to above is particularly intriguing, suggesting the happiness courses may had have an effect on students. The post-test phase scores actually are above the college average. However, the same result occurred with the recreational course, so this result needs to be interpreted with caution and it is recommended that future research examine cause and effect.

Figure 5. Pre, post, and total average happiness scores of the three groups, as compared to the college student average.

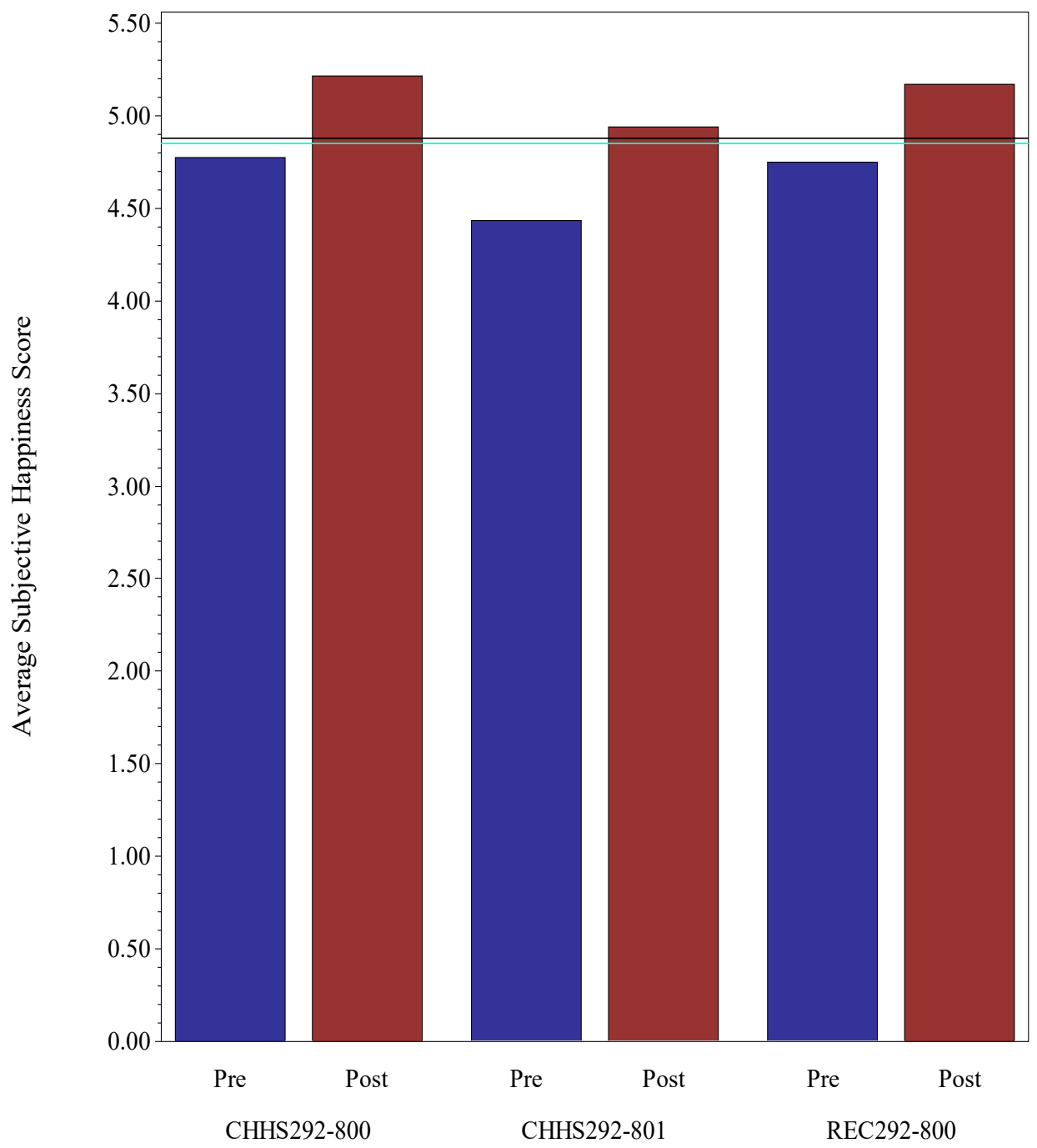

College Students' Average Score (black line) $=4.88$

College Students' Average Score from this Study (teal line) $=4.85$

The work of Davies and Mendenhall (1998) may explain this observation, as their findings yielded positive student responses and intentions of life changes. The course may have had an impact on its participants that was genuine. 
This same authentic change is seen in the present study regarding happiness levels. Despite the lack of significance, the data clearly indicated a measurable change in happiness.

\section{CONCLUSIONS}

In 2014, a national sample of college freshmen's self-rated emotional health was at its lowest level ever (Eagan, Stolzenberg, Ramirez, Aragon, Suchard, \& Hurtado, 2014). As universities increase programming options to meet students' increasing needs, offering a "happiness" course, which provides students with coping skills and strategies to increase happiness may be a worthwhile addition to a campus wellness portfolio. Often, student related mental health issues fall entirely on student affairs professionals to manage. By implementing a happiness course, academic affairs may provide students with strategies to handle life's challenges in a positive way.

Studies have shown that intervention programs related to happiness can positively contribute to well-being (Bolier, Haverman, Westerhof, Riper, Smit, \& Bohlmeijer, 2013; Proyer, Gander, Wellenzohn, \& Ruch, 2016; Sin \& Lyubomirsky, 2009). Whether delivered face-to-face or online, a happiness course may be an effective addition to a university's wellness offerings. Happiness interventions are a way to promote positive health, and courses have shown an ability to help students learn strategies to improve happiness.

This study provided preliminary evidence of happiness levels in college students enrolled in 5-week online courses. Although pre-post measures indicated an increase of subjective happiness in college students, regardless of enrollment in a happiness course or a recreational course, the results provide descriptive data that adds to the literature on the current happiness levels of college students. Happiness scores were fairly consistent as compared to those in previously studied college student populations (i.e., 4.88 or above during post), but scores were slightly lower at the beginning of the courses in our study (i.e., 4.66).

Additionally, with the escalating popularity of online formats, studying online happiness courses is salient. Because increasingly more students are enrolling in web-based courses, it makes sense to determine if targeted happiness interventions have an impact on happiness when delivered in this format. This study did not compare online to traditional face-to-face formats or modalities, as the focus was on course content and applied coping strategies. However, it is suggested that future research delve more into the differences between delivery format when implementing course-based happiness interventions. The present study contributes to the research regarding the online course delivery format, in that it demonstrates the potential of the online environment to be effective in increasing happiness. The implications of having a potentially more widespread impact on diverse populations, both within and outside academia through evidence-based online interventions, is a worthwhile area of investigation.

While we found no significant differences in subjective happiness levels between happiness and recreation students, the data and findings resulting from this study can certainly be used to inform future research. In addition, the limitations of this study, which were previously discussed, can be addressed through additional studies. Specifically studying the impact of university happiness courses delivered in a variety of formats is recommended, in addition to other evidence-based well-being interventions aimed at teaching coping strategies and managing stress. It is clear that the more psychologically vulnerable college student population can benefit from such efforts, as their emotional wellbeing does not seem to be moving in a more positive direction. 


\section{REFERENCES}

Block, A., Udermann, B., Felix, M., Reineke, D., \& Murray, S. R. (2008). Achievement and satisfaction in an online versus a traditional health and wellness course. Journal of Online Learning and Teaching, 4(1), 57-66. http://jolt.merlot.org/vol4no1/block0308.pdf

Bögels, S., Hoogstad, B., van Dun, L., de Schutter, S., \& Restifo, K. (2008). Mindfulness training for adolescents with externalizing disorders and their parents. Behavioural and Cognitive Psychotherapy, 36(2), 193-209. https://doi.org/10.1017/S1352465808004190

Bolier, L., Haverman, M., Westerhof, G. J., Riper, H., Smit, F., \& Bohlmeijer, E. (2013). Positive psychology interventions: a meta-analysis of randomized controlled studies. BMC public health, 13(1), 119. https://doi.org/10.1186/1471-2458-13-119

Cohn, M. A., Fredrickson, B. L., Brown, S. L., Mikels, J. A., \& Conway, A. M. (2009). Happiness unpacked: positive emotions increase life satisfaction by building resilience. Emotion, 9(3), 361. https://doi.org/10.1037/a0015952

Davies, R. S., \& Mendenhall, R. (1998). Evaluation comparison of online and classroom Instruction for HEPE 129-Fitness and Lifestyle Management Course. [Evaluation Project]. Department of Instructional Psychology and Technology, Brigham Young University. Retrieved from http:// files.eric.ed.gov/ fulltext/ED427752.pdf

Duckworth, A. L., Steen, T. A., \& Seligman, M. E. (2005). Positive psychology in clinical practice. Annual Review of Clinical Psychology, 1, 629-651. https://doi.org/10.1146/annurev.clinpsy.1.102803.144154

Eagan, K., Stolzenberg, E. B., Ramirez, J. J., Aragon, M. C., Suchard, M. R., \& Hurtado, S. (2014). The American freshman: National norms fall 2014. Los Angeles: Higher Education Research Institute, UCLA.

Kim, J., \& Lee, J. E. R. (2011). The Facebook paths to happiness: Effects of the number of Facebook friends and self-presentation on subjective well-being. CyberPsychology, Behavior, and Social Networking, 14(6), 359364. https://doi.org/10.1089/cyber.2010.0374

Kubzansky, L., \& Viswanath, K. (2016, June 10). TIME - The science of happiness: New discoveries for a more joyful life. New York: Time Inc. Books.

Lambert, L., Passmore, H. A., \& Joshanloo, M. (2018). A positive psychology intervention program in a culturallydiverse university: Boosting happiness and reducing fear. Journal of Happiness Studies, 1-22.

https://doi.org/10.1007/s10902-018-9993-z

Lockyer, L., Patterson, J., \& Harper, B. (1999). Measuring Effectiveness of Health Education in a Web-based Learning Environment: a preliminary report. Higher Education Research \& Development, 18(2), 233-246. https://doi.org/10.1080/0729436990180206

Lyubomirsky, S. (2007). The how of happiness: A scientific approach to getting the life you want. New York: Penguin Press.

Lyubomirsky, S., \& Lepper, H. (1999). A Measure Of Subjective Happiness: Preliminary Reliability And Construct Validation. Social Indicators Research, 46, 137-155. https://doi.org/10.1023/A:1006824100041 
National Institute of Mental Health. (2017). Major Depression. Retrieved from

https://www.nimh.nih.gov/health/statistics/major-depression.shtml

National Institute of Mental Health. (2017). Mental Illness. Retrieved from

https://www.nimh.nih.gov/health/statistics/mental-illness.shtml

National Institute of Mental Health. (2017). Suicide. Retrieved from

https://www.nimh.nih.gov/health/statistics/suicide.shtml

Proyer, R. T., Gander, F., Wellenzohn, S., \& Ruch, W. (2016). Addressing the role of personality, ability, and positive and negative affect in positive psychology interventions: Findings from a randomized intervention based on the authentic happiness theory and extensions. The Journal of Positive Psychology, 11(6), 609-621. https://doi.org/10.1080/17439760.2015.1137622

Reilly, K. (2018). Record Numbers of College Students Are Seeking Treatment for Depression and Anxiety-But Schools Can’t Keep Up. Time Magazine. March 19, 2018. https://time.com/5190291/anxiety-depressioncollege-university-students/

SAS Institute Inc 2013. SAS/ACCESS 9.4 ® Interface to ADABAS: Reference. Cary, NC: SAS Institute Inc. The data analysis for this paper was generated using SAS software. Copyright, SAS Institute Inc. SAS and all other SAS Institute Inc. product or service names are registered trademarks or trademarks of SAS Institute Inc., Cary, NC, USA.

Seligman, M. E. (2004). Can happiness be taught? Daedalus, 133(2), 80-87. https://doi.org/10.1162/001152604323049424

Sin, N. L., \& Lyubomirsky, S. (2009). Enhancing well-being and alleviating depressive symptoms with positive psychology interventions: A practice-friendly meta-analysis. Journal of clinical psychology, 65(5), 467-487. https://doi.org/10.1002/jclp.20593

Tosevski, D. L., Milovancevic, M. P., \& Gajic, S. D. (2010). Personality and psychopathology of university students. Current Opinion in Psychiatry, 23(1), 48-52. https://doi.org/10.1097/YCO.0b013e328333d625

U.S. Department of Education, National Center for Education Statistics. (2014). Enrollment in distance education courses, by state: Fall 2012. Retrieved from http:/ /nces.ed.gov/pubs2014/2014023.pdf

Author correspondence should be directed to:

Casey Murdoch Rodowicz

University of North Carolina Wilmington (Alumni)

School of Health and Applied Human Sciences

501 S. College Ave

Wilmington, NC 28403

casey.c.murdoch@gmail.com 
Laura M. Morris, Ed.D.

Assistant Professor

University of North Carolina Wilmington

School of Health and Applied Human Sciences

501 S. College Ave

Wilmington, NC 28403

spiveyl@uncw.edu

Cara L. Sidman, PhD

Clinical Assistant Professor

Arizona State University

College of Health Solutions

550 N. 3rd St

Phoenix, AZ 85004

cara.sidman@asu.edu 